\title{
Neurocognitive Investigation of the Stroop Effect
}

\author{
Stroop Etkisinin Nörobilişsel Açıdan Íncelenmesi
}

\author{
Fatih Bal
}

\begin{abstract}
:
The Stroop Color and Word Test (SCWT) is a widely used neuropsychological test to assess the ability to inhibit cognitive interference that occurs when processing of a particular stimulus feature interferes with simultaneous processing of a second stimulus feature, known as the Stroop Effect. Two reasons for the popularity of the Stroop effect have been suggested. Despite its statistically reliable effect, there is no adequate explanation for the effect. The aim of this study is to examine the Stroop effect from a neurocognitive perspective. When we look at the literature, there are mostly experimental and statistical studies. In line with the hypothesis that the Stroop effect does not have neurocognitive effects, the method of "document scanning-literature scanning" was used as a way of data collection in the research.
\end{abstract}

Keywords: Stroop Effect, Neurocognition, Neuropsychology

PhD., Faculty of Arts and Sciences, Psychology Department, Sakarya University, Sakarya-Turkey, Orcid İd: 0000-0002-99742033

Address of Correspondence/Yazışma Adresi: Faculty of Arts and Sciences, Psychology Department, Sakarya University, Sakarya-Turkey, E-mail: fatihbal@ sakarya.edu.tr

Date of Received/Geliş Tarihi: 30.07.2021, Date of Revision/Düzeltme Tarihi: 20.08.2021, Date of Acceptance/Kabul Tarihi: 31.08.2021, Date of Online Publication/Çevirimiçi Yayın Tarihi: 01.09.2021

Citing/Referans Gösterimi: Bal, F. (2021). Neurocognitive Investigation of The Stroop Effect, Cyprus Turkish Journal of Psychiatry \& Psychology, 3(3): 223-228

(C) 2021 The Author(s). Published by Cyprus Mental Health Institute / Cyprus Turkish Journal of Psychiatry and Psychology (www.ktppdergisi.com). This article is an open access article distributed under the terms and conditions of the Creative Commons Attribution 4.0 license which permits use, sharing, adaptation, distribution and reproduction in any medium or format, provided the original work is properly cited and is not used for commercial purposes. http://creativecommons.org/licenses/by/4.0/ 


\section{Öz:}

Stroop Renk ve Kelime Testi (SCWT), belirli bir uyaran özelliğinin işlenmesi, Stroop Etkisi olarak bilinen ikinci bir uyaran özelliğinin aynı anda işlenmesini engellediğinde ortaya çıkan bilişsel müdahaleyi engelleme yeteneğini değerlendirmek için yaygın olarak kullanılan bir nöropsikolojik testtir. Stroop etkisinin popülaritesinin iki nedeni öne sürülmektedir. İstatistiksel olarak güvenilir etkisine rağmen etki için yeterli bir açıklamanın olmamasıdır. Bu çalışmanın amacı, Stroop etkisinin nörobilişsel açıdan incelenmesidir. Alan yazına bakıldığında daha çok deneysel ve istatistiki araştırmalara rastlanmaktadır. Stroop etkisinin nörobilişsel etkileri bulunmamaktadır hipotezi doğrultusunda araştırmada veri toplama yolu olarak, "belge tarama- literatür tarama" yönteminden yararlanılmıştır.

Anahtar Kelimeler: Stroop Etkisi, Nörobiliş, Nöropsikoloji

\section{Giriş}

Psikolojide, Stroop etkisi, otomatik ve kontrollü bilgi işleme arasındaki tepki süresindeki gecikmedir; burada, sözcüklerin adları, sözcükleri yazdırmak için kullanılan mürekkebin rengini adlandırma yeteneğine müdahale eder.

Stroop testi, bireylerin kelimenin anlamından farklı bir renkte basılan kelimelerin bir listesini görüntülemelerini gerektirir. Katılımcılara, mümkün olduğunca hızlı bir şekilde, kelimenin kendisini değil, kelimenin rengini adlandırmakla görevlendirilir.

\section{Stroop ve Stroop Etkisi}

Stroop ve Stroop Etkisi, John Ridley Stroop'un "Studies of Interferences in Serial Verbal Reactions" (Stroop, 1935) adlı kitabını yayınladıktan sonra adını almıştır. Stroop'un orijinal çalışmasında üç öğe kullanılmıştır. Bunlar; siyah mürekkeple basılan renklerin adları, belirtilen renkten farklı mürekkeple basılan renklerin adları ve verilen her rengin kareleridir. El yazması, üç farklı uyaran kullanan üç deneyden oluşuyordu. İlki, katılımcılardan siyah mürekkeple yazılmış renkli sözcükleri (uyaran 1) ve renk sözcüklerini mürekkebin renginden bağımsız olarak (uyaran 2) adlandırmalarını istedi. İkinci deneyde, katılımcılardan yazılı kelimeden bağımsız olarak renk kelimelerinin rengini söylemeleri (uyaran 2) ve ayrica karelerin rengini (uyaran 3) adlandırmaları istendi. Üçüncü deney, katılımcıları, birlikteliğin etkilerini hesaba katmak için üç farklı uyaran boyunca farklı uygulama aşamalarında test etti. Stroop, katılımcıların ikinci deneyde renk adlandırma işlemini tamamlamasının, birinci deneydeki renk kelimesinin adını okumaktan daha uzun sürdüğünü kaydetti. Mürekkebin rengini, rengin ve kelimenin uyumsuz olduğu renk kelimesine karşı1t olarak adlandırmak, okumanın üstünlüğü nedeniyle daha fazla zihinsel müdahaleye sahiptir. Zihin, bir kelimenin anlamsal anlamını "otomatik olarak" belirleyebilir, ancak bunun yerine kelimenin rengini adlandırmak için böyle bir yanitı kasitlı olarak engeller (Stroop, 1935).

Stroop üç ana uyaran türünü içerecek şekilde zamanla değişime uğramıştır. Bunlar; nötr, uyumlu ve uyumsuz uyaranlardır. Nötr uyaranlar, siyah mürekkepli veya renkli şekillerdeki renkli sözcüklerden oluşabilenleri içerir. Uyumlu uyaranlar, sözcükle aynı mürekkep renginde yazılan renk sözcükleridir (mavi mürekkeple yazılmış "mavi"), oysa uyumsuz uyaranlar, renk sözcüğ̈üle eşleşmeyen bir mürekkep rengiyle yazılanlardır (kırmızı mürekkeple yazılmış "mavi”). Stroop etkisinin keşfinden bu yana, görevdeki müdahale veya belirginliklerin farklı yönlerini sorgulamak için çeşitli varyasyonlar geliştirilmiştir. Örneğin, renkli kelime görevleri genellikle "soğuk" olarak sınıflandırılır, yani duygusal veya motivasyon yüklü sözcükleri kullanan "sıcak" görevlerle karşılaştırıldığında, genellikle duygusal durumlarla ilişkilendirilmezler (Heitz, Unsworth ve Engle, 2005).

Uyaranların ve tepkilerin tesadüfi özelliklerinin belirgin etkiler ürettiği bir başka görev örneği, katılımcılardan, kelimenin ne olduğuna bakılmaksızın kelimelerin sunulduğu mürekkebin rengini adlandırmalarının istendiğ bir görevdir. Katılımcılar bu talimata uyabilir ve kararla kesinlikle alakasız tüm bilgileri görmezden gelebilirlerse, mürekkep rengi sınıflandırılacak olan kelimenin mürekkep rengi adıyla eşleşip eşleşmediği önemli olmayacaktır. Örneğin, yeşil mürekkeple yazılan "KIRMIZI" kelimesine "yeşil" demek, yeşil mürekkeple yazılan "YEŞİL" kelimesine "yeşil" demekten daha fazla zaman almamalıdır.

Stroop'un (1935) keşfettiği gibi, insanların "KIRMIZI" kelimesi yeşil mürekkeple gösterildiğinde "yeşil" demek, "YEŞILL" kelimesi yeşil mürekkeple gösterildiğinden çok daha uzun sürer. Nedeni yanıt rekabetine kadar takip edilebilir. "YEŞIL" kelimesini görmek otomatik olarak "yeşil" yanıtı etkinleştirir, ancak bu yanıt kırmızı mürekkebe yanıt olarak "kırmızı" demekle bağdaşmaz. İki olası yanıtla "yeşil" ve "kırmızı" mücadeleyi çözmek için fazladan zamana ihtiyaç vardır. Yönetici kontrol süreçleri, talimatlara uygun yanıtı seçmek için çevrimiçi hale gelir ve bu da fazladan zaman alır.

Stroop etkisi, tepki süresi (RT) araştırmasının en güvenilir ve sağlam fenomenlerinden biridir (MacLeod, 1991). Gözlenen sonuçlar, insanların bilinçli olarak renkleri etiketlemekten ziyade kelimeleri bilinçli olarak okuma deneyimine sahip oldukları gerçeğini yansıtabilir ve bu iki süreci kontrol eden mekanizmalardaki bir fark1 gösterebilmektedir. Stroop etkisi, katılımcıların renkli kelimeleri yüksek sesle söylemek yerine yazdıkları deneylerde gösterilmiştir (Logan ve Zbrodoff, 1998). Beklenebileceği gibi, yazma bağlamında Stroop deneyini elde etmek için, katılımcıların çok yetenekli daktilo yazarları olması gerekir, aksi takdirde okudukları kelimeleri otomatik olarak yazma eğilimleri olmaz. Bu fikre dayanarak, Stroop etkisi, klavyede veya diğer 
performans alanlarında olsun, uyaranlara verilen yanıtların otomatikliğinin bir ölçüsünü sağlar.

Stroop etkisinde, katılımcıya gösterilen sözcüğün çağrıştırdığı yanıt, sözcüğün mürekkebiyle çağrılan yanıta müdahale eder. Diğer görevlerde, olası tepkiler arasında bu tür müdahaleler de önerilmektedir. Olası yanıtlar arasındaki veya bunlar arasındaki ilişkilerden dolayı ister dolaylı ister açık olarak çağrılsın, seçim RT'lerinde yapılan değişiklikler, yanıt-yanıt (R-R) uyumluluk etkileri olarak bilinir.

R-R uyumluluk etkisinin ilk raporlarından biri, deneklerin iki farklı seçim RT koşulunda gerçekleştirildiği bir deneyden gelmiştir (Kornblum, 1965). Birinde, sağ elin işaret parmağı ile bir düğmeye basmak ve sağ elin orta parmağıyla bir düğmeye basmak arasında seçim yaptılar. Yine sağ elin işaret parmağı ile düğmeye basmak ve sol elin orta parmağıyla düğmeye basmak arasında seçim yaptılar. Sinyaller iki durumda da aynıydı, ancak ortak sağ işaret parmağ 1 için seçim RT'si, alternatif yanıt sol orta parmak olduğunda, alternatif yanıt sağ orta parmak olduğunda olduğundan daha kısaydı. Bu nedenle, aynı sinyale aynı yanıt için RT seçimi, diğer olası yanıtın kimliğinden etkilenmiştir.

Kornblum (1965), bu sonucun nedeninin aynı elin parmakları arasında, farklı ellerin parmakları arasında olduğundan daha fazla rekabet veya engelleme olduğunu öne sürdü. Aynı elin işaret parmağı ve orta parmağ mekanik olarak birbirine bağlıdır. Buna karşılık, bir elin işaret parmağ 1 ve orta parmak mekanik olarak daha bağımsızdır. Sağ orta parmağınızı veya sol orta parmağınızı sallarken sağ işaret parmağınızı sabit tutmaya çalışarak bu farkı kendiniz gösterebilirsiniz. Aynı elin orta parmağını oynatırken işaret parmağını sabit tutmak neredeyse imkansızdır, ancak diğer elin orta parmağını sallarken işaret parmağını sabit tutmak kolaydır. İki elin parmakları arasındaki daha fazla bağımsızlık, bu parmaklardan biriyle yanit vermeye hazırlanmay kolaylaştırır.

R-R uyumluluğunun bu açılaması için daha fazla destek, katılımcıların sağ işaret parmağı yanıtıyla yanıt vermeye hazır olmaya teşvik edildiği ve çoğu denemede bu parmakla yanıt vermelerinin istendiği bir deneyden geldi. Bununla birlikte, diğer denemelerde, sağ orta parmak veya sol orta parmak gibi başka bir olası parmakla yanıt vermeleri istendi (Rosenbaum ve Kornblum, 1982). Sağ orta parmakla yapıldığında daha az hazır yanıta geçiş süresi, sol orta parmakla yapıldığından daha uzundu, sağ işaret parmağ sağ işaret parmağ katılımcılar diğer el tepkisi için ikincil bir hazır olma durumunu sürdürmeyi daha kolay buldular.

\section{Stroop Etkisinin Nörobilişsel Açıdan İncelenmesi}

Stroop etkisi, beynin bilgiyi nasıl işlediği hakkında çok şey ortaya çıkaran basit bir olgudur. Stroop etkisi, farklı bir rengin adını hecelemek için kullanıldığında fiziksel bir rengi adlandırmakta zorluk yaşama eğilimimizdir. Bu basit bulgu hem psikoloji hem de nörobilişsel araştırmalarda büyük bir rol oynamaktadır.

Stroop testi hem deneysel hem de klinik psikolojide "belirli bir uyaran özelliğinin işlenmesi ikinci bir uyaran özelliğinin aynı anda işlenmesini engellediğinde ortaya çıkan bilişsel müdahaleyi engelleme yeteneğini değerlendirmek" için kullanılır (Scarpina ve Tagini, 2017). Stroop testi, bir kişinin seçici dikkat kapasitesini ve becerilerini, işlem hızını ölçmek ve diğer testlerin yanı sıra genel yürütücü işlem yeteneklerini değerlendirmek için kullanılabilir. Seçici dikkat "hangi bilgilerin daha fazla işleme ve farkındalığa erişim sağlanacağını ve hangilerinin göz ardı edileceğini" seçer. Stroop etkisi ile ilgili olarak, kelimelerin rengini belirlemek, sadece metni okumaktan daha fazla dikkat gerektirir. $\mathrm{Bu}$ nedenle, bu teori beynimizin renklerin kendileri yerine yazılı bilgileri işlediğini öne sürmektedir. İki tür bilişsel işlememiz, otomatik ve kontrollü düşünmeyi içerir. Stroop etkisi ile ilgili olarak, beyin muhtemelen kelimeyi okur çünkü okuma renkleri tanımaktan çok otomatik bir işlemdir. İşleme hızı teorisi, yazılı kelimeleri renkleri işleyebileceğimizden daha hızlı işleyebileceğimizi öne sürer. $\mathrm{Bu}$ nedenle, kelimeyi zaten okuduktan sonra rengi tanımlamak zordur. Paralel dağıtılmıș ișleme teorisinde, beynin farklı görevler için farklı yollar oluşturduğunu öne sürer. Bu nedenle adı, rengi veya metni daha kolay olan önemli bir rol oynayan yolun gücüdür.

Stroop, otomatik yanıtların inhibisyonunu içeren ve sıklıkla frontal lob fonksiyonlarını değerlendirmek için kullanılan klasik bir paradigmadır. Çok sayıda çalışma, bu fenomenden sorumlu belirli beyin bölgelerini belirlemeye çalışmış ve iki kilit bölgeyi belirlemiştir. Bunlar; anterior singulat korteks (ACC) ve dorsolateral prefrontal kortekstir (DLFPC). Hem MRI hem de fMRI taramalar1, Stroop testi veya ilgili görevleri tamamlarken ACC ve DLPFC'de aktivite gösterir (Milham vd, 2003). DLPFC, bellek ve yürütme işlevine yardımcı olur ve görev sırasındaki rolü, renk algısını etkinleştirmek ve kelime kodlamasını engellemektir. ACC, uygun yanıtı seçmekten ve dikkat kaynaklarını uygun sekilde tahsis etmekten sorumludur (Banich ve ark., 2000).

Catıșma izleme sistemi, bilișsel kontrolden sorumlu merkezler üzerinde bir etki uygulayarak, çatışma meydana geldiğinde işleme sürecine daha güçlü müdahale etmelerine neden olur. Bu mekanizmalar genellikle, Stroop görevi gibi uyaranlar ve tepkiler arasındaki uyum veya uyumsuzluk tarafindan ortaya çıkarılan doğal bir müdahalenin olduğu belirli görevler aracılığıyla araştırılır. Duygusal çatışma araștırmalarında, dorsal anterior singulat korteks (ACC) ile ilgili bir hipotez, kısmen çatışmaların ortaya çıkmasına işaret etmeye hizmet etmesi ve böylece telafi edici ayarlamaları tetiklemesidir (Satorres, Oliva, Escudero ve Meléndez, 2020).

Stroop etkisini tekrar tekrar test eden sayısız araştırma, birkaç önemli tekrar eden bulgu ortaya koymaktadır (van Maanen, van Rijn ve Borst, 2009). Bunlar;

- $\quad$ Semantik müdahale: Mürekkebin rengini nötr uyaranların adlandırılması (renklerin yazılı bir sözcük olarak değil, yalnızca bloklar halinde gösterildiği) uyumsuz uyaranlardan (kelimenin basılı renginden farklı olduğu durumlarda) daha hızlıdır.

Semantik kolaylaştırma: Uyumlu uyaranların mürekkebini adlandırmak (kelime ve yazdırılan rengin uyumlu olduğu yerde) nötr uyaranlardan daha hızlıdır.

- $\quad$ Stroop eș zamansızlığı: Önceki iki bulgu rengi adlandırmak yerine sözcüğü okurken ortadan kaybolmakta, sözcükleri okumanın renkleri adlandırmaktan çok daha otomatik olduğu iddiasını desteklemektir. 
Diğer deneyler, orijinal Stroop test paradigmasını ek bulgular sağlamak için biraz değiştirmiştir. Bir çalışma, katılımcıların nötr kelimelerin aksine duygu kelimelerinin rengini adlandırmada daha yavaş olduklarını bulmuştur (Larsen, Mercer ve Balota, 2006). Başka bir deney, panik bozukluğu ve OKB'si olan katılımcılar arasındaki farkl11kkları inceledi. Tehdit kelimelerini uyaran olarak kullansalar bile panik bozukluğu, $\mathrm{OKB}$ ve nötr katılımcıların renkleri işleme yetenekleri arasında bir fark olmadığını bulmuşlardır (Kampman, Keijsers, Verbraak, Näring ve Hoogduin, 2002). Üçüncü bir deney, kelime ve renk işleme yerine süre ve sayısal işlem arasındaki ilişkiyi araştırdı. Katılımcılara art arda iki nokta dizisi gösterildi ve (1) hangi serinin daha fazla nokta içerdiği veya (2) serinin ilk noktasından son noktasına kadar hangi serinin daha uzun sürdüğü soruldu. Uyumsuzluk, ekranda daha uzun süre daha az nokta gösterildiğinde meydana geldi ve uyumlu bir seri, daha uzun süren daha fazla nokta içeren bir seri tarafından işaretlendi. Araştırmacılar, sayısal ipuçlarının süre işlemeye müdahale ettiğini buldular. Daha uzun süre daha az nokta gösterildiğinde, katılımcıların ekranda hangi nokta kümesinin daha uzun süre göründüğünü anlamaları daha zor olduğu bulunmuştur (Dormal, Seron ve Pesenti, 2006). Sayısallığın işlenmesi ile süre arasında bir fark vardır. Bu deneyler yalnızca Stroop'un ilk çalışmasının açtığı araştırma kapılarının tamamını göstermekle kalmamakta, aynı zamanda beynimizde meydana gelen tüm karmaşı işlem ilişkilerine de 1şık tutmaktadır.

Stroop görevinin amacı beyinde oluşan enterferansı ölçmektir. İlk paradigma, o zamandan beri (daha önce bahsedildiği gibi süre ve çokluk gibi) diğer girişim biçimlerini ölçmek için birkaç farklı şekilde benimsenmiştir. Ek varyasyonlar, resim ve kelime işleme, yön ve kelime işleme, rakam ve sayı işleme ve merkezi ve çevresel harf tanımlama arasındaki etkileşimi ölçer (MacLeod, 2016). Stroop görevi ayrıca seçici dikkat, işlem hızı ve bilişsel esnekliği ölçmek için bir mekanizma olarak kullanılır (Howieson, Lezak ve Loring, 2004). Ek olarak Stroop görevi, demans, depresyon veya DEHB gibi beyin hasarı veya zihinsel bozuklukları olan popülasyonları incelemek için kullanılmıştır (Lansbergen, Kenemans ve van Engeland, 2007). Depresyonu olan bireyler için duygusal bir Stroop görevi "keder", "şiddet" ve "acı" gibi olumsuz kelimelerin "saat", "kapı" ve "ayakkabı" gibi daha nötr kelimelerle birlikte kullanıldığı bir görevi” şeklinde geliştirilmiştir. Araştırmalar, depresyonla mücadele eden bireylerin, olumsuz bir kelimenin rengini nötr bir kelimeden daha yavaş söyleme ihtimalinin daha yüksek olduğunu ortaya koymaktadır (Frings, Englert, Wentura ve Bermeitinger, 2010). Stroop testi, DEHB'li yetişkinlerde girişim kontrolü ve görev seti koordinasyonunu değerlendirirken kullanılmaktadır (King, Colla, Brass, Heuser ve von Cramon, 2007). Golden (1976) yaptığı araştırmada, beyin hasarı olan ve olmayanları ayırt etmede yüzde 88,9 oranında doğru olduğunu bulmuştur. Daha sonraki çalışmalar bu bulguları doğrulamıştır. Stroop testi sıklıkla travmatik beyin hasarı hastalarında seçici dikkati değerlendirmek için kullanılmıştır (Ben, Nguyen ve van Lieshout, 2011).

Organizmanın hem içinden hem de dışından müdahaleye karş1 koruma, davranış organizasyonunda prefrontal korteksin en önemli işlevlerinden biri olarak tanımlanmıştır. Girişime karşı savunmasızlık nedeniyle zaman içinde tutarlı yönlendirilmiş dikkati sürdürememe, frontal lob hasarı olan maymunlarda temel bir eksikliktir
(Fuster, 1989). Stroop testi, insanlarda enterferans sorununu doğrudan değerlendirir ve maymunlarla yapılan araştırmalarda kullanılan yap/yapma görevlerine büyük ölçüde benzerdir (Struss, 1991). Bu testte, bir renk adlandırma görevindeki tepki süresi, hedef uyaranda uyumsuz semantik bilgilerin sunulmasından kaynaklanan parazit tarafindan artırılır, örneğin özneden harflerin rengini (örneğin kırmızı) söylemesi istendiğinde bir monitör ekranında YEŞIL kelimesini oluşturulması şeklinde gerçekleştirilir (McLeod, 1991).

Stroop testi performansındaki anormallik, net fokal frontal lezyonları olmayan hastalarda frontal disfonksiyonları göstermek için sıklıkla kullanılmıştır. Örneğin, Parkinson (Brown ve Marsden, 1991), huntington hastalıklarında (Brandt, 1991) ve ayrıca psikiyatrik hastalığ hastalarda şizofreni (Cohen ve Servan, 1992) ve obsesifkompulsif bozukluk (Martlnot ve ark., 1990) frontal tutulumu göstermek için kullanılmıştır. Stroop'un frontal lob testi olarak kullanımı, esas olarak, 1974'te bu tür interferansın çözülmesinde yer alan fonksiyonlar için bir sol frontal konum öneren Perret'in (1974) bulgularına dayanmaktadır. PET çalışmaları, sağ ön singulatın Stroop görevinin dikkat yönlerinde rol oynadığı sonucuna varmıştır (Bench ve ark., 1993; Pardo, Pardo, Janet ve Ralchle, 1990).

\section{Sonuç}

Beynimize anıları depolamak, uyumak, düşünmek vb. gibi pek çok şey yapmasını söyleyebiliriz. Peki neden ona bir rengi adlandırmak kadar kolay bir şey yapmasını söyleyemiyoruz? Bu çok küçük yaşta öğrendiğimiz bir şey değil mi? Araştırmacılar bu soruyu analiz etmiş̧ler ve Stroop etkisinin ortaya çıkışını açıklamaya çalışan çok sayıda farklı teori geliştirmiş̧lerdir (Sahinoglu ve Dogan, 2016). John Ridley Stroop, bu alanda gelecekte yapilacak çok sayıda araştırmanın temelinin atılmasına yardımcı olmuştur.

Stroop etkisi, insan psikolojisi üzerinde gerçek bir etkisi olmayan büyüleyici bir deney gibi görünebilir. Gerçekte, bilgiyi işleme şeklimiz hakkında çok şey gösterir ve içgüdüsel hızlı düşünmemizi geçersiz kılma yeteneğimizi değerlendirmemize yardımcı olmaktadır. Stroop görevinde gözlemlenen etkiler, insanların seçici dikkat kapasitesinin ve bazı uyaranların dikkat kontrolünden kaçma yeteneğinin açık bir örneğini sağlamaktadır (Cohen, Dunbar ve McClelland, 1990).

Stroop'un orijinal deneyleri de dahil olmak üzere birçok çalışma, uygulamanın Stroop çıkarımını azaltabileceğini öne sürmektedir. Bunun öğrenme becerilerimiz, çoklu görev yeteneğimiz ve alışkanlıklarımızı nasıl oluşturduğumuz üzerinde etkileri vardır. Stroop etkisinin keşfedilmesi, otomatik ve kontrollü düşünme, seçici dikkat, bilişsel işlememiz ve daha fazlasını içeren çalışmalarda ve deneylerde rol oynamaya devam ermektedir. Stroop etkisi hiçbir zaman kesin olarak açıklanamasa da psikoloji ve nörobilim araştırmalarında uzun yıllardır referans alınan denenmiş ve gerçek bir ölçüt olarak kullanılmaktadır.

Stroop görev paradigmasının çok yönlülüğü, psikoloji içindeki çok çeşitli alanlarda faydalı olmaktadır. Bir zamanlar sadece kelime ve renk işleme arasındaki ilişkiyi inceleyen bir test olan bu test, o zamandan beri ek işleme 
müdahalelerini araştırmak ve psikopatoloji ve beyin hasarı alanlarına katkıda bulunmak için genişletilmiştir. Stroop görevinin geliştirilmesi, sadece beyin mekanizmalarımızın nasıl çalıştığına dair yeni bilgiler sağlamakla kalmaz, aynı zamanda kendimiz hakkında daha fazla şey keşfetmeye devam ettikçe psikolojinin genişleme ve geçmiş araştırma yöntemlerini geliştirme gücüne de 1şık tutmaktadır.

\section{Beyannameler}

Etik Onayı ve Katılım Onayı

Uygulanamaz.

\section{Yayın İzni \\ Uygulanamaz.}

\section{Veri ve Materyallerin Mevcudiyeti}

Mevcut çalışma sırasında herhangi bir veri kümesi oluşturulmadığı veya analiz edilmediğinden veri paylaşımı bu makale için geçerli değildir.

\section{Çıkar çatışması \\ Uygulanamaz.}

Finansman

Uygulanamaz.

Yazar Katkıları

Makale FB tarafindan yazılmıştır. Yazar makalenin son halini okumuş ve onaylamıştır.

\section{Teşekkürler}

Uygulanamaz.

\section{Kaynaklar}

Banich, M.T., Milham, M.P., Atchley, R., Cohen, N.J., Webb, A., Wszalek, T., Kramer, A.F., Liang, Z.P., Wrigh, A., Shenker, J., \& Magin, R. (2000). fMRI studies of Stroop tasks reveal unique roles of anterior and posterior brain systems in attentional selection. Journal of cognitive neuroscience, 12(6), 988-1000.

Ben, B.M.D., Nguyen, L.L.T., \& van Lieshout, P.H.H.M. (2011). Stroop effects in persons with traumatic brain injury: Selective attention, speed of processing, or color-naming? A meta-analysis. Journal of the International Neuropsychological Society, 17(02), 354-363.

Bench, C.J., Frith, C.D., Grasby, P.M., Friston, K.J., Paulesu, E., Frackowiak, R.S.J., \& Dolan, R.J. (1993). Investigations of the functional anatomy of attention using the Stroop test. Neuropsychologia 31, 907-922.

Brandt, J. (1991). Cognitive impairment in Huntington's disease: insight into the neuropsychology of the striatum. In F. Boller, \& J. Grafman (Eds.), Handbook of neuropsychology (pp. 241 264). Amsterdam: Elsevier.

Brown, R.G., \& Marsden, C.D. (1991). Dual task performance and processing resources in normal subjects and patients with Parkinson's disease. Brain, 114, 215-231.

Cohen, J.D., \& Servan-Schreiber, D. (1992). Context, cortex, and dopamine: A connectionist approach to behaviour and biology in schizophrenia. Psychol. Rev., 99, 45-77.

Cohen, J.D., Dunbar, K., \& McClelland, J.L. (1990). On the control of automatic processes: A parallel distributed processing account of the Stroop effect. Psychological Review, 97(3), 332361.

Dormal, V., Seron, X., \& Pesenti, M. (2006). Numerosityduration interference: A Stroop experiment. Acta psychologica, 121(2), 109-124

Fuster, J.M. (1989). The prefrontal cortex. anatomy, physiolofly, and neuropsycholoqy of the frontal lobe. New York: Raven Press.

Frings, C., Englert, J., Wentura, D., \& Bermeitinger, C. (2010). Decomposing the emotional Stroop effect. Quarterly journal of experimental psychology, 63(1), 42-49

Golden, C.J. (1976). Identification of brain disorders by the Stroop Color and Word Test. Journal of Clinical Psychology, 32(3), 654-658.

Heitz, R.P., Unsworth, N., \& Engle, R.W. (2005). Working memory capacity, attention control, and fluid intelligence. In O. Wilhelm, \& R.W. Engle (Eds.), Handbook of understanding and measuring intelligence (pp. 61-77). New York: Sage Publications.
Howieson, D.B., Lezak, M.D., \& Loring, D.W. (2004). Orientation and attention. Neuropsychological assessment, 365367.

Kampman, M., Keijsers, G.P., Verbraak, M. J., Näring, G., \& Hoogduin, C.A. (2002). The emotional Stroop: a comparison of panic disorder patients, obsessive-compulsive patients, and normal controls, in two experiments. Journal of anxiety disorders, 16(4), 425-441.

King, J. A., Colla, M., Brass, M., Heuser, I., \& von Cramon, D. (2007). Inefficient cognitive control in adult ADHD: evidence from trial-by-trial Stroop test and cued task switching performance. Behavioral and Brain Functions, 3(1), 42.

Kornblum, S. (1965). Response competition and/or inhibition in two-choice reaction time. Psychonomic Science, 2(2), 55-56.

Lansbergen, M.M., Kenemans, J.L., \& van Engeland, H. (2007). Stroop interference and attention-deficit/hyperactivity disorder: a review and meta-analysis. Neuropsychology, 21(2), 251.

Larsen, R.J., Mercer, K.A., \& Balota, D.A. (2006). Lexical characteristics of words used in emotional Stroop experiments. Emotion, 6(1), 62

Logan, G.D., \& Zbrodoff, N.J. (1998). Stroop-type interference: Congruity effects in color naming with typewritten responses. Journal of Experimental Psychology: Human Perception and Performance, 24(3), 978-992.

MacLeod, C.M. (1991). Half a century of research on the Stroop effect: An integrative review. Psychological Bulletin, 109, 163 203

MacLeod, C.M. (1992). The Stroop task: The "gold standard" of attentional measures. Journal of Experimental Psychology, 121(1), 12-14.

MacLeod, C.M. (2016). The stroop effect: Encyclopedia of color science and technology. New York: Springer.

Martlnot, J.L., Allilaire, J.F., Mazoyer, B.H., Hantouche, E., Huret, J.D., Legaut-Demare, F., Deslauriers, A.G., Hardy, P., Pappata, S., Baron, J.C., \& Syrota, A. (1990). Obsessive ompulsive disorder: A clinical, neuropsychological and positron emission tomography study. Acta Psychlatr, 82, 233242

Milham, M.P., Banich, M.T., Claus, E.D., \& Cohen, N.J. (2003). Practice-related effects demonstrate complementary roles of anterior cingulate and prefrontal cortices in attentional control. Neuroimage, 18(2), 483-493.

Pardo, J.V., Pardo, P.J., Janet, K.W., \& Ralchle, M.E. (1990). The anterior cingulate cortex mediates processing selection in the 
Stroop attentional conflict paradigm. Proc. Natl. Acad. Sci. 87, 256-259.

Perret, E. (1974). The left frontal lobe of man and the suppression of habitual responses in verbal categorial behaviour. Neuropsycholooia 12, 323-330.

Rosenbaum, D.A. \& Kornblum, S. (1982). A priming method for investigating the selection of motor responses. Acta Psychologica, 51(3), 223-243

Sahinoglu B, \& Dogan G. (2016). Event-related potentials and the stroop effect. Eurasian J Med, 48(1), 53- 57.

Satorres, E., Oliva, I., Escudero, J., \& Meléndez, J.C. (2020). Conflict monitoring on an emotional Stroop task. Comparison of healthy older adults and patients with major neurocognitive disorders due to probable AD. Journal of Clinical and Experimental Neuropsychology, 1-10.

Scarpina, F., \& Tagini, S. (2017). The stroop color and word test. Frontiers in Psychology, 8, 1-8.

Stroop, J.R. (1935). Studies of interference in serial verbal reactions. Journal of Experimental Psychology, 18, 643-662.

Stuss, D.T. (1991). Interference effects on memory functions in post leucotomy patients. An attentional perspective. In H.S. Levin, H.M. Eisenberg \& A. L. Benton (Eds.), Frontal lobe function and dysfunction (pp. 157-172). New York: Oxford University Press.

van Maanen, L., van Rijn, H., \& Borst, J.P. (2009). Stroop and picture word interference are two sides of the same coin. Psychonomic Bulletin \& Review, 16(6), 987-999. 